\title{
Function-related Secondary User Needs and Secondary Data? A Crit- ical Examination of Some Central Concepts in the Modern Theory of Lexicographical Functions
}

Marcin Overgaard Ptaszynski, Centre for Lexicography, Aarhus School of Business, University of Aarhus, Aarhus, Denmark (maop@asb.dk)

\begin{abstract}
The aim of this article is to contribute to the development of the modern theory of lexicographical functions by offering a critical examination of the following concepts associated with it: primary needs, primary data, secondary needs, secondary data, function-related needs, and functionrelated data. By way of introduction, a presentation of the basic tenets of the theory is offered, followed by a description of the general characteristics of secondary needs and data. Next, on the basis of both a critical analysis of the theory and an examination of selected data types in existing lexicographical products, it is argued that all user needs and all data that satisfy those needs are function-related. The distinction between the concepts function-related and usage-related is thus rejected. Since this has serious implications for the relation between secondary needs and data on the one hand and primary needs and data on the other, this relation is subsequently reconsidered. This leads to a redefinition of all the concepts examined. It is also explained why an ideal state of lexicography, where secondary needs and data do not exist, cannot be achieved in the real world.
\end{abstract}

Keywords: DICTIONARY, LEXICOGRAPHY, LEXICOGRAPHICAL FUNCTION, PRIMARY NEED, PRIMARY DATA, SECONDARY NEED, SECONDARY DATA, FUNCTION-RELATED NEED, FUNCTION-RELATED DATA, EXTRA-LEXICOGRAPHICAL SITUATION, INTRALEXICOGRAPHICAL SITUATION, COMMUNICATIVE FUNCTION, COGNITIVE FUNCTION, OPERATIVE FUNCTION, TEXT RECEPTION, TEXT PRODUCTION, TRANSLATION

Opsomming: Funksieverwante sekondêre gebruikersbehoeftes en sekondêre data? 'n Kritiese ondersoek na 'n aantal kernbegrippe in die moderne teorie van leksikografiese funksies. Die doel van hierdie artikel is om by te dra tot die ontwikkeling van die moderne teorie van leksikografiese funksies deur 'n kritiese ondersoek aan te bied van die volgende begrippe wat daarmee verbind word: primêre behoeftes, primêre data, sekondêre behoeftes, sekondêre data, funksieverwante behoeftes en funksieverwante data. Ter inleiding word 'n aanbieding van die basiese beginsels van die teorie gegee, gevolg deur 'n beskrywing van die algemene eienskappe van sekondêre behoeftes en data. Vervolgens, op grond van sowel 'n kritiese ontleding van die teorie as 'n ondersoek van uitgesoekte datatipes in bestaande leksikografiese produkte, word daar geredeneer dat alle gebruikersbehoeftes en alle data wat daardie behoeftes bevredig, funksieverwant is. Die onderskeid tussen die konsepte funksieverwant en gebruikersver- 
want word sodoende verwerp. Omdat dit ernstige implikasies vir die verhouding tussen sekondêre behoeftes en data aan die een en primêre behoeftes en data aan die ander kant het, word hierdie verhouding gevolglik heroorweeg. Dit lei tot 'n herdefiniëring van al die ondersoekte begrippe. Daar word ook verduidelik waarom 'n ideale toestand van die leksikografie waar sekondêre behoeftes en data nie bestaan nie, nie in die werklike wêreld bereik kan word nie.

Sleutelwoorde: WOORDEBOEK, LEKSIKOGRAFIE, LEKSIKOGRAFIESE FUNKSIE, PRIMÊRE BEHOEFTE, PRIMÊRE DATA, SEKONDÊRE BEHOEFTE, SEKONDÊRE DATA, FUNKSIEVERWANTE BEHOEFTE, FUNKSIEVERWANTE DATA, EKSTRALEKSIKOGRAFIESE SITUASIE, INTRALEKSIKOGRAFIESE SITUASIE, KOMMUNIKATIEWE FUNKSIE, KOGNITIEWE FUNKSIE, OPERATIEWE FUNKSIE, TEKSONTVANGS, TEKSPRODUKSIE, VERTALING

\section{Introduction}

In his seminal work on the modern theory of lexicographical functions (hereafter referred to as the MTLF), Tarp defines the lexicographical function as "the satisfaction of the specific type of lexicographically relevant need that may arise in a specific type of potential user in a specific type of extra-lexicographical situation" (Tarp 2008a: 81). A lexicographically relevant need arising in an extra-lexicographical situation is invariably a need for information that can be satisfied by a lexicographical product. This would be, for example, the need to know what the Afrikaans word woordeboek means, which can be satisfied by looking up the word in, e.g., an Afrikaans-English dictionary. ${ }^{1}$ A type of potential user is identifiable on the basis of carefully selected criteria, such as the user's mother tongue, their proficiency in a specific foreign language, and their knowledge of a specific subject or science (Tarp 2008a: 54 et seq.).

The current version of the MTLF distinguishes between four types of extra-lexicographical situations: communicative, cognitive, operative and interpretative. The communicative type, embracing situations in which a potential dictionary user is in need of linguistic assistance in order to solve a problem arising in an act of communication, is subdivided into the following subtypes: text reception, text production, text editing, and text revision (in all cases with regard to either the user's mother tongue or a particular foreign language), as well as translation (to and from the user's mother tongue or between two foreign languages). Situations of the cognitive type are those in which a potential user of a lexicographical product needs help with acquisition of new knowledge about a given subject (or with revision of what they already know). The communicative and cognitive types of situation are well-established concepts in the MTLF, and are described in a variety of publications, such as Tarp (2006, 2008a) or Bergenholtz and Tarp (2003). Recent developments of the theory have offered descriptions of two other situation types. The operative situation type is defined by Tarp (2008b: 126 et seq.) as a type of situation in which a potential user of a lexicographical product seeks "directions and instructions on how to proceed in specific situations". 2 The interpretative situation type has not been 
given a definitive description yet, but is tentatively defined as a type of situation in which a potential user of a lexicographical product needs help with the interpretation of non-linguistic signs (Tarp 2009).

On the basis of the definition of a lexicographical function quoted and explicated above it is possible to construct an example of a functional relationship, i.e. a relationship between a type of lexicographically relevant need, a particular type of potential user and a specific type of extra-lexicographical situation. Thus, a Dane who is highly proficient in their mother tongue but less so in English may experience a problem with text reception in connection with reading a contemporary, non-specialised English text. The problem may, for example, consist in the fact that the Dane does not understand the English word ambled in the sentence I just kept talking to them as they ambled by ignoring $m e .{ }^{3}$ The lexicographically relevant need that will arise in this situation is the need for information about the meaning of the word ambled. In order to satisfy this need, the user can consult a lexicographical product with an appropriate function, in this case an English-Danish dictionary or a monolingual English learner's dictionary. In either case it should be a general-purpose dictionary designed to help a Danish user with text reception in English. Assuming that the user knows that ambled is a verb and is the past tense form of amble, they will look up the infinitive form in the dictionary and find the Danish equivalent or an English definition, both of which will satisfy their need for information.

Certainly, the above scenario represents an idealised version of reality. It excludes the possibility of the user being unable to find the data they are looking for, e.g. if they do not know how to spell the word they are trying to look up. Likewise, it does not allow for the possibility that the user may be unable to interpret the data they have found, e.g. if they do not understand the meaning of some terms included in the definition of the word they have looked up. In both cases the user would develop another need for additional data that would help them find or interpret the data they were looking for before they consulted a particular lexicographical product. To account for such problems, the MTLF distinguishes between the so-called primary and secondary user needs. According to Tarp (2008a: 41 et seq.), primary needs always arise in an extralexicographical situation, i.e. before the consultation of a dictionary or another lexicographical product. They are to be distinguished from secondary user needs, which arise in an intra-lexicographical situation, i.e. during the consultation of a particular lexicographical product. Primary needs are satisfied by primary lexicographical data, while secondary needs are, correspondingly, satisfied by secondary lexicographical data. Since primary needs underlie the function of a lexicographical product, they are also known as function-related needs, whereas secondary needs are also referred to as usage-related needs (Tarp 2008a: 41). The binary opposition between function-related and usagerelated applies not only to needs but also to data which are meant to satisfy these needs (Tarp 1998: 128 et seq.).

This article offers a critical examination of the distinction between the 
notions of function-related and usage-related, which for a variety of reasons proves to be problematic. To support the view that all needs and data are related to the function of a lexicographical product, a critical analysis of the MTLF is undertaken with regard to the available works on the theory itself, as well as to selected data types. Consequently, the concepts of primary and secondary needs and data are re-examined and redefined with regard to the notion of the lexicographical function.

\section{Secondary needs and data: general characteristics and examples}

An analysis of the distinction between function-related and usage-related requires a thorough understanding of the concepts to which these terms apply. As mentioned above, in the MTLF the predicate function-related is used with regard to primary needs and primary data. The rationale behind this is clear: primary needs underlie the function of a given lexicographical product, and the function, in turn, decides the presence, form and content of primary data. Whatever determines or is determined by the function must be function-related. Therefore, the concepts of primary needs and data need no further elaboration in this context. The term function-related is not applied to the concepts of secondary needs and secondary data. In order to establish whether this is a felicitous approach, it is necessary to examine how these concepts are defined and used in the MTLF.

Tarp (2008a: 42) states that "secondary user needs (also known as usagerelated needs) [...] do not arise until an actual lexicographical situation occurs, when the potential user turns into an actual dictionary user and may need guidance in the form of secondary lexicographical data to find and interpret the primary lexicographical data needed to satisfy their primary user needs". Secondary needs are "both needs for information and needs for instruction and education" (Tarp 2008a: 57 et seq.), the MTLF distinguishing three types of such needs:

(1) "Secondary needs related to specific dictionary consultation", which are needs "for information that can help users to find and confirm the [primary] data required".

(2) "Secondary needs related to the user's linguistic and subject-specific qualifications", which are needs for information that can help users to extract information out of primary data.

(3) "Secondary needs related to general or specific dictionary usage", which include the needs for "general education in lexicography, general instruction in dictionary usage, information about the specific dictionary, and instruction in the use of specific dictionary".

Each type of secondary need can be satisfied by the corresponding types of data. Dictionaries thus contain "data that helps users to find the specific data 
that is relevant in the situation in question, and data that may help users to interpret it - followed by data that users can use to extract general information about the dictionaries in question" (Tarp 2008a: 58), i.e. data types that satisfy the above-mentioned needs of type 1,2, and 3 respectively. Other types of secondary data also exist, e.g. data concerning the content, quality and reliability of the dictionary, which the users may need to access before buying and using the dictionary (Tarp 2008a: 58).

The relation between types of secondary needs and lexicographical solutions satisfying these needs is illustrated by Tarp (2008a: 57 et seq.) with several examples. For instance, a secondary need related to specific dictionary consultation can be represented by a situation in which "a Danish user wishing to understand the Afrikaans word skepe needs to know that skepe is the plural form of skip and that additional information can be found under the lemma skip". As regards secondary needs related to the user's linguistic and subjectspecific qualifications, "users who have very little knowledge about a specific discipline need simple lexicographical data about this discipline" in order to be able to "extract information out of complex data".

Secondary needs are also specified in Tarp's description of user needs in particular extra-lexicographical situations. For instance, in connection with the reception of non-specialised texts in their mother tongue, a Danish user may develop secondary needs with regard to the following information categories: lemmata, orthography, orthographical variants (and mistakes) as lemmata, irregular inflection forms as lemmata, word combinations as lemmata, word class, and gender (Tarp 2008a: 70 et seq.).

Examples of secondary data types that may be included in a dictionary are offered in an earlier work on the MTLF and include the preface, the user's guide and the consumer's label (Tarp 1998: 129).

Finally, two other important characteristics of secondary needs need to be mentioned. First, secondary needs can be satisfied "both within and outside the framework of specific dictionaries" (Tarp 2008a: 58). Second, it is possible to combine classes of information data that satisfy primary needs with those that are related to secondary needs, provided that the classes in question "are not in direct contradiction to each other" (Tarp 2008a: 76).

\section{Critical examination of selected concepts in the MTLF}

\subsection{Function-related vs. usage-related needs and data}

There appear to be good reasons to question the validity of this distinction, as it is possible to argue that not only primary but also secondary user needs and data are function-related. Several arguments in favour of such a view can actually be found in the existing works on the MTLF. Others can be drawn on the basis of an analysis of selected data types and the types of need they are meant to satisfy. 


\subsubsection{Evidence from the MTLF}

Some incentive to reconsider the distinction between function-related and usage-related needs and data is provided by Tarp's example of a secondary need quoted above. On the one hand, it is certainly correct to maintain that the secondary data which inform the Danish user about the Afrikaans word skepe being the plural form of skip and redirect them to the lemma skip are usagerelated, insofar as the user intends to look up the form skepe in the dictionary. On the other hand, it would be risky to claim that these data are not functionrelated. The situation described in the example is one of a user who wants to solve a problem connected with text reception and is seeking assistance in a dictionary having the corresponding function. It is solely in connection with the user's particular type of primary need, reflected in the function of the dictionary, that the secondary need appears and is satisfied by the presence of specific secondary data. If the function of the dictionary was other than that of helping a (specific type of) Danish user with text reception in Afrikaans, the user's secondary need to find out that skepe is the plural of skip would be neither predicted by the lexicographer nor satisfied by that dictionary. The presence of the secondary data in a dictionary and, in the first place, the lexicographer's prediction about the user's need that requires it, thus appear to be inextricably bound with the function of that dictionary.

This view is reinforced by the fact that secondary needs are specified by Tarp (2008a) in the description of user needs in particular extra-lexicographical situations. The secondary needs experienced by a user solving a problem concerning text reception in their mother tongue are, for example, different from the needs arising in connection with text production in the same user's mother tongue. Only the latter include, among others, the needs for information about the meaning of lemmata, the meaning of idioms and the meaning of proverbs (Tarp 2008a: 72). It follows thus that secondary needs are not universal but dependent on the extra-lexicographical situation. If this is the case, they are necessarily related to the function of a dictionary. Certainly, the above-mentioned relations between particular secondary needs on the one hand and information data categories on the other are only true if the analysis of user needs is restricted, in accordance with Tarp (2008a), to Danish, Danish texts and the use of non-specialist language. The needs for specific types of secondary data will vary across languages, and consequently, across dictionaries. For example, a secondary need for information about gender makes little sense with regard to dictionaries of Finnish, which has no grammatical gender, but is definitely conceivable with respect to dictionaries of Polish or German, both of which distinguish between three genders in nouns.

Further encouragement to consider secondary user needs to be functionrelated can be found in Tarp's comment on combining information classes related to primary and secondary needs. As mentioned earlier, the classes can be combined only if they are not in direct contradiction to each other. To 
explain how this principle works, the following example concerning all communicative situations restricted to the user's mother tongue is offered: "either [...] the same demands must be made with regard to completeness in terms of the meaning of lemmata; or [...] it is at least possible to find a common denominator" (Tarp 2008a: 76). This implies that if the same demands cannot be made, or if a common denominator cannot be found, then information classes related to particular primary and secondary needs are in direct contradiction to each other and cannot be combined. In other words, in order to be included in a dictionary, information classes related to secondary needs must be compatible with those related to primary needs. And as primary needs determine the function of the dictionary and are function-related, it is thus hard to argue that the same does not apply to secondary needs. This observation is strengthened by the following statement from another publication on the principles of the MTLF: "no data whatsoever should be included in a dictionary if it cannot be argued on the basis of its respective functions" (Bergenholtz and Tarp 2003: 177).

Moreover, it seems that the above implication reveals a weakness of the MTLF. By determining the function of a dictionary and the scope of all classes of information to be included in it, primary needs necessarily determine the extent to which the dictionary can satisfy secondary needs. This is hardly reconcilable with the claim that the satisfaction of secondary needs is vital for the satisfaction of primary needs. If both statements are correct, then primary needs seem to determine the extent to which they themselves can be satisfied by a dictionary. This is clearly undesirable, since it allows for a situation where a primary need calls only for partial satisfaction.

\subsubsection{Analysis of selected data types}

An examination of data types in existing lexicographical products also provides a reason to question the division of needs and data into those which are function-related and those which are not. Since primary data are by definition function-related, the scope of the analysis will be restricted to data types that in accordance with the MTLF would be considered as secondary data. However, before any analysis is undertaken, it bears mention that it will exhibit an approach directly incompatible with the basic tenets of the MTLF. The point of departure adopted here is the specific data (types) that may or may not be present in particular dictionaries, rather than the specific needs that these data are supposed to address. This is what Tarp (2008a: 10) calls a contemplative approach, represented by various lexicographical theories (e.g. Hayashi (1978), Wiegand (e.g. 1984), and to a significant degree Svensén (2004) and Yong and Peng (2007)). By contrast, the MTLF is transformative, i.e. oriented towards generating rules that will govern the form and content of future dictionaries and other lexicographical products. Nevertheless, the contemplative approach will not be entirely dismissed here, as it does shed light on the problem of the dis- 
tinction between function-related and usage-related needs and data. Selected data types examined below are divided into two broad categories: data found in the outside matter of a dictionary and those included in the microstructure of a dictionary.

\subsubsection{Data included in the outside matter}

Two examples of data types often found in the outside matter will be considered here: the user's guide and the table of contents. Even in the absence of any lexicographical theory, both the lexicographer and the dictionary user would intuitively feel that these data types are somehow different from such data as, e.g. the pronunciations of headwords or the examples illustrating their use. It is difficult to imagine a situation in which a (specific type of) potential user would consult a dictionary to satisfy their primary need with the data offered in the user's guide or the table of contents. ${ }^{4}$

The user's guide is classified by Tarp (1998: 129) as secondary and thereby not a function-related data type. However, this claim is refuted by the content of existing dictionaries, some of which were actually compiled in accordance with the principles based on the MTLF. Examples in point include the DanishEnglish and English-Danish dictionaries of accounting (Nielsen et al. 2004 and 2007 , respectively). In each case the user's guide is structured around the functions of the dictionary. The data it contains are grouped under the headings corresponding to the user's primary needs and, by extension, the dictionary functions, e.g. "Hjælp til at oversætte engelske tekster til dansk" ('Assistance in translating English texts into Danish') (Nielsen et al. 2007: 12). The functionoriented approach to the composition of the user's guide is also advocated in metalexicographical literature, e.g. in Nielsen (2006) and Ptaszynski (2008). Thus, in spite of being a secondary data type, the user's guide appears to be function-related.

A similar claim could be made with regard to the table of contents (if it is to be regarded as lexicographical data in the first place). While definitely usage-related, it presents the user with an overview of the entire content of the dictionary, most (if not all) of which is determined by the function of the dictionary. A dictionary illustrating it particularly well is Nielsen et al. (2007). The table of contents guides the reader, e.g. to the relevant, function-dependent section in the user's guide as well as to additional material in the back matter, such as examples of formats of financial statements in English. The primary function of the dictionary is to provide assistance in translating English accounting texts into Danish. If the function were different, the content of both the user's guide and the back matter, and, in consequence, the table of contents, would be different too.

At this point one might argue that the function of a dictionary clearly determines the form and contents but not the presence of the user's guide or the table of contents in it. Any dictionary, regardless of its function, normally con- 
tains such data types. However, dictionaries are not the only kinds of lexicographical products. Tarp (2008b: 126 et seq.) incorporates handbooks, manuals, and how-tos into the domain of products which can include lexicographically structured data. Such products are meant to fulfil the operative function. This sheds more light on the status of such data types as the user's guide. They do not seem to appear in certain lexicographical products whose primary function is operative, e.g. manuals. By contrast, they are usually included in dictionaries, which are designed to assist the user in communicative and/or cognitive situations. This means that the user's guide is indeed function-related, as not only its form and content but also its presence is determined by the function of a particular lexicographical product. The case of the table of contents is more difficult. Although its form and content depend on the function of the specific lexicographical product, its presence is probably determined by other factors, such as the medium. For instance, printed reference works often contain tables of contents, while internet-based products rarely do (unless one admits the sitemap into this category).

\subsubsection{Data included in the microstructure}

A thorough examination of all possible data types included in the microstructures of a wide range of dictionaries would be clearly beyond the scope of the present discussion. It would also be unnecessary, as a single entry is sufficient to provide arguments in favour of the view that there exists a relation between secondary data and the function of the dictionary containing these data. All that is required is that the analyzed entry includes any data supposed to satisfy a secondary need, and that it is possible to determine the function of the dictionary containing that entry. Both conditions are met with regard to the entry baffle in The Pocket Oxford Spanish Dictionary reproduced below:

baffle /'bæfəl/ $v t$ (a) (perplex) desconcertar* (b) (frustrate) 〈efforts〉 frustrar.

The primary function of the dictionary is to aid English-speaking learners of Spanish with translation (nothing is said about the direction of the translation, but since the dictionary is bidirectional, it possibly aims to assist the user in translation both to and from Spanish). Thus the relevant primary data in the entry baffle will be the Spanish equivalents of the headword, i.e. desconcertar and frustrar. By contrast, "(a)", "(b)", "(perplex)", "(frustrate)", and "〈efforts〉" are clear examples of secondary data. This can be established in two ways. First, it is inconceivable that any primary user need related to translation would be satisfied by these data. Second, the sole purpose of all these data appears to be to guide the user to the choice of the correct translation equivalent. The user's guide confirms that this assumption is correct with regard to the data type exemplified by "〈efforts $\rangle "$. This data type is described as "words often used with the headword, shown to help select the correct translation for each context". 
The reasons for including data types exemplified by "(a)" and "frustrate", which are termed "sense divisions" and "sense indicators" respectively are not specified (Carvajal and Horwood 2000: ix et seq.). However, they seem to be the same as those for the inclusion of the data type exemplified by "〈efforts〉". If this is the case, the data can only serve to help the user find the required primary data, and must, accordingly, be classified as secondary data.

There should be no doubt as to whether the Spanish equivalents of baffle given in the entry are function-related or not. All primary data are by definition related to the function of the dictionary. The same question is more difficult to address with respect to the secondary data mentioned above. A satisfactory answer must take into account the fact that the data types represented by "(a)", "(frustrate)" and "(efforts〉" do not form a homogeneous category. The last of these data types appears to be more readily classifiable as function-related than the other two. As stated above, the user's guide reveals that the purpose of such data is to help the user select the correct translation. Since the function of the dictionary is that of helping the user with translation, these data must be function-related. This assumption is proved right if a corresponding entry in a dictionary with a different function is considered. For example, in a dictionary for Spanish-speaking users seeking assistance in text reception in English, such data would probably not be included, as the user does not need to know the collocational preferences of the headword (as exemplified by the relation of efforts to baffle) in order to grasp its meaning (cf. Tarp 2008a: 149).

The case of "(a)" and "(frustrate)" is slightly more complicated. Sense divisions and sense indicators also commonly appear in dictionaries with other functions than just that of helping the user with translation. However, it is still possible to establish the relation between these data types and the function of the lexicographical product that contains them. To begin by stating what is apparently obvious: sense divisions and sense indicators make sense only in lexicographical products addressing such user needs that arise either in connection with acts of verbal communication or during the acquisition of knowledge about the vocabulary of a particular language. In other words, their use is mostly confined to dictionaries. Such types of data would be absent from lexicographical products that aim to satisfy operative user needs, e.g. lexicographically structured manuals and handbooks.

Even if the scope of the discussion is restricted to dictionaries, the use of sense divisions and sense indicators still seems to depend on the function of a particular dictionary. One might argue that the presence of such data types depends in the first place on certain linguistic properties of the headword. After all, it is the fact that some words, like book or cry, have more than one established sense, ${ }^{5}$ but other words, like stopcock, pneumonia or lemonade do not, that makes it possible to use any kind of sense discriminators in some entries but not in others. However, even in the case of polysemous words, the decision to represent a particular number of senses in the specific entry lies ultimately with the lexicographer. The outcome of this decision depends exclusively on 
the function of the dictionary. For instance, a dictionary for adult native speakers of English, designed primarily for the acquisition of knowledge about the English vocabulary, e.g. OED, may include four senses of taxi (n.), while a learner's dictionary intended for text reception and text production in English, e.g. LDOCE, will include only one. In the latter case, ipso facto no sense divisions are used. The use of sense indicators is subject to similar restrictions. They are often used in dictionaries for learners, such as LDOCE, but not, for instance, in dictionaries aiming to help users with text reception in their mother tongue, e.g. Merriam-Webster Online Dictionary. An adult native-speaker would normally be able to retrieve the relevant information about the particular sense of the headword from the definition or an illustrative example (Atkins and Rundell 2008: 214).

\subsection{Secondary vs. primary needs and data}

If, as argued above, secondary data seem to be function-related, are they definable as a category? In other words, what distinguishes them from primary data? An obvious answer, based on the definition of secondary needs presented earlier, is that the need to access secondary data does "not arise until an actual lexicographical situation occurs" (Tarp 2008a: 41). However, this statement appears to create more problems than it aims to solve. First, the typology of secondary needs includes "secondary needs related to general or specific dictionary usage", such as the needs for general education in lexicography and general instruction in dictionary usage. This type of secondary need could surely occur in an extra-lexicographical situation, independently of any primary need that would trigger an actual lexicographical situation with regard to a specific dictionary. The need for a course in dictionary use could be a part of someone's general education. It does not have to be a step on the way to satisfy their need to solve a particular problem by means of a specific dictionary. A related problem is that of a prospective user accessing data about a specific dictionary before actually buying and using it. Conscious buyers would carefully select a dictionary so that it would suit their needs, but that does not necessarily mean that they would do it only after they have experienced a specific problem that can be solved by a particular dictionary.

Second, as was observed earlier, secondary needs can be satisfied within the framework of specific dictionaries as well as outside this framework. If the latter is the case, assistance can be provided by general courses in dictionary use as well as by workbooks with exercises in the use of a specific dictionary (Tarp 1998: 128 et seq.). ${ }^{6}$ These are, however, not the only possibilities. For instance, even though an ideal dictionary should be thought to contain all the data necessary for the interpretation of the primary data included in it, the user may still decide to satisfy their secondary need by means of a different dictionary. And whenever the user turns to another lexicographical product - be it a dictionary, an encyclopaedia, or a lexicographically structured workbook or 
manual - what was originally the secondary need becomes a new primary need, as the situation changes from intra-lexicographical to extra-lexicographical.

Third, the above definition of secondary needs does not take into account that these needs can often be satisfied by means of the primary data included in a given dictionary. For example, an advanced learner of English using an English monolingual dictionary in connection with text reception may experience difficulty with understanding the definition of the word they are looking up. If the problem is caused by the fact that the definition contains a word unfamiliar to the user, ${ }^{7}$ it can often be solved by looking up this word in the same dictionary. The definition provided in the relevant entry may be (and usually is) what the lexicographer intended to be a piece of primary data, included in the dictionary in order to satisfy needs arising in an extra-lexicographical situation. It is, of course, possible to object to such reasoning by arguing that it entails a mixture of two different perspectives. The same data are being viewed here in terms of their relation to the user on the one hand and to the lexicographer on the other. According to the adopted perspective, they are classified as data intended to satisfy secondary or primary needs. And if a general theory of lexicography, like the MTLF, is supposed to account for the needs-adapted access to data, the user's standpoint is certainly more important than the lexicographer's. Considered on the surface, such an argument seems valid. However, it fails to take into account that the user cannot access any data that would satisfy their need, until the lexicographer has physically placed and organized these data in a lexicographical product. A conscientious lexicographer certainly begins working on the dictionary project by conducting an examination of both primary and secondary needs the potential user of that dictionary might have. On this basis, all decisions regarding the inclusion and presentation of all primary and secondary data are made. Still, regardless of how careful the analysis of user needs may have been, it is impossible for the lexicographer to make absolutely correct predictions about what would be primary and secondary data for a specific user in all possible acts of dictionary use. To do so, one would virtually have to know all specific lexicographically relevant needs of that user and all facts relevant to establishing the user profile (and assume that all these variables are constant). Consequently, one would need to produce lexicographical products on an individual basis. Since this is not and never will be possible in practice, to produce even the best lexicographical product it is necessary to assume that the lexicographer's perspective matches that of the user's, despite the fact that these two standpoints only approximate each other. This assumption, in turn, allows for situations where a secondary need is satisfied by means of primary data.

From the above it follows that the difference between primary and secondary data is difficult, if not downright impossible to determine on the basis of the nature of the situation (extra-lexicographical vs. intra-lexicographical) that triggers the need for either kind of data. It seems more appropriate to speak 
about the use of specific data as primary or secondary. But even this would only be true provided that (a) a given secondary need arises in connection with a specific primary need and (b) the user seeks the satisfaction of both needs in the same dictionary (or other kind of lexicographical product). It is, on the other hand, reasonable to say that some data types, e.g. the user's guide, the table of contents, sense discriminators, or labels indicating the part of speech, are more likely to satisfy secondary rather than primary needs. They may also be used to satisfy secondary needs more often than it would be the case with other data types, such as the explications of the meaning of the headword.

Some data types, e.g. the user's guide, are used to satisfy the user's secondary needs regardless of the function of the dictionary containing them (although, as was demonstrated earlier, the function still determines the contents, form and presence of the data). The use of other data types to satisfy the user's secondary needs will be determined by the function of the dictionary. This is e.g. the case with data concerning gender in dictionaries of Danish for native speakers. According to Tarp (2008a: 71 et seq.), such data are used to satisfy the user's primary needs in dictionaries intended for text production, and to satisfy the user's secondary needs in dictionaries for text reception. Lastly, data types like definitions of headwords may be used to satisfy both primary and secondary needs (though perhaps not with the same frequency) in the same dictionary.

\section{Secondary needs as a lexicographical necessity}

If secondary needs seem to be a volatile category and secondary data cannot be distinguished clearly from primary data even with respect to the same dictionary, why not reject both concepts? After all, this is what the MTLF would see as an ideal state of lexicography. In an ideal lexicographical situation, there are no secondary needs and, by extension, no secondary data. This conclusion can be drawn from the description of the ideal dictionary presented by Bergenholtz (2008). The dictionary in question is like the Junior Woodchucks Guidebook, used by Donald Duck's nephews Huey, Dewey and Louie. "The answer [to the user's problem] is always correct and always understandable." This means that secondary needs for interpreting the primary data never occur. Neither do users ever experience a secondary need in connection with accessing the primary data. "They find the answer without writing any question at all. The 'computer' is able to read their thoughts and tell them exactly what they need to know." 8

The entire theory thus seems to rest on the axiom that for every need for information there are specific data which can satisfy this need exhaustively. This may seem obvious. In fact, however, the acceptance of the axiom as the supreme principle of the theory and practice of lexicography has two serious implications. First, it obliges lexicographers to strive towards the reduction of secondary needs to the absolute minimum. These needs appear only if primary needs cannot be satisfied directly, and in the ideal world this is never the case. 
Second, whenever the interpretation of primary data in a particular dictionary poses a problem to the user, and the resulting secondary need cannot be solved by means of the same dictionary, the blame can conveniently be laid on the lexicographer (for not having implemented the axiomatic principle correctly) or on the user (for choosing an inappropriate tool to satisfy their need). Whichever is the case, the principle itself is by no means rendered invalid.

Nevertheless, as the absolute minimum of secondary needs cannot be defined universally, the above principle is not possible to observe in the real world. Two problems will help to illustrate the point. First, even in a lexicographical product perfectly geared to a specific user profile, it would still be impossible for the lexicographer to predict and absolutely avoid all situations in which the user finds the specific primary data difficult to understand. To do so, one would have to assume that the user's command of a particular language, their knowledge of a particular subject matter, or their ability to perform a particular operation never deteriorates. Unfortunately, this is not how the human mind works. The same primary data, e.g. the definition of a headword, can be fully understandable for the user on one occasion but not on another, if they happen to have forgotten the meaning of as much as a single word contained in it. In the latter case, a secondary need would appear, even though it may not have been predicted by the lexicographer or may not have been relevant for the user at the moment of purchasing the dictionary. Thus, to avoid the occurrence of such secondary needs, the user would need as many dictionaries as there are extra-lexicographical situations that would trigger their use. Such a scenario is obviously unrealistic.

Next, even if the user's cognition is assumed to be perfect, in many cases there would still be a need for data whose aim is to guide the user to the desired primary data. An example in point is the need to represent such data as, e.g. verb forms in Spanish. According to the adopted axiomatic principle, it should be possible to construct a lexicographical product that would help, for instance, an English user with little or no command of Spanish to understand the simple sentence Hablamos español. ('We speak Spanish.') The form hablamos is normally not lemmatized in dictionaries for text reception in Spanish. If it is, the users are, at best, redirected to the entry hablar to learn that the headword means 'speak', and are subsequently referred to the tables of verb conjugation in the grammar section appended in the back matter, where they learn that hablamos is the first person plural present of hablar. This is, however, not what the user was hoping for. Their primary need was to understand the meaning of hablamos, not of hablar, and certainly not to be directed to an exposition of Spanish grammar. In an ideal dictionary, all forms of all inflectable lexical items are lemmatized and supplied with all the relevant data the user requires to satisfy their primary need. This is certainly not possible in real dictionaries. It would overburden the macrostructure of every dictionary, even an internetbased one, where space considerations are of minor importance compared to printed dictionaries. Therefore, the number of forms lemmatized and given a 
full entry must be reduced, and if such forms as hablamos are to be lemmatized at all, the entire entry will only guide the user to other data.

Moreover, the idea of minimizing the amount of secondary needs and data reveals another fact about the axiom. The principle based on it reflects an idealized world of essentially linguistic, communicative primary user needs. Secondary needs that appear in connection with these needs are relatively uncomplicated, because they can often be satisfied by simple data, e.g. a sense discriminator, a cross-reference to an entry for the canonical form of a verb, or definitions of the defining vocabulary in a monolingual dictionary for text reception. The same is not the case with respect to lexicographical tools designed to help the user in cognitive situations, especially those of the systematic type (cf. Tarp 2008b: 123 et seq.), where the user seeks assistance in connection with a regular study of a specific subject field. For example, a dilettante in music who wishes to understand the notion of the musical scale must become familiar with such concepts as octave, interval or pitch class. The lexicographer can, of course, provide cross-references to the corresponding entries (as is done, e.g. in the article musical scale in Wikipedia). This, however, would probably not satisfy the user's primary need. Having consulted the entries for the abovementioned concepts, they might understand the definition of musical scale, but their knowledge of what a musical scale actually is would still be very far from exhaustive if they do not know the concepts of whole tone, semitone, major, minor, and chromatic. This looks like an endless chain of interrelated secondary needs, all of which should ideally be predicted by the lexicographer. The data necessary to satisfy them are complex (they comprise entire entries) and form an open set (it is not possible to predict how many entries the user will have to consult until they consider their knowledge of the subject matter studied to be satisfactory). These needs thus cannot be reduced to any minimum.

One could, of course, argue that such a view of systematic cognitive needs is inadequate. The primary need itself arises in a situation that presupposes a systematic use of a lexicographical product. Having to consult more than one entry should then perhaps be considered as part of the realization of the primary need rather than as a series of secondary needs following the first lookup. On the other hand, in terms of the very act of dictionary use, this scenario bears a resemblance to another one, in which the user needs to look up two (or perhaps several) entries in the dictionary in order to be able to arrive at the correct interpretation of the primary data satisfying the primary need for information in connection with, e.g. text reception in a foreign language. Why then should the MTLF be inclined to identify all the data searches following the first look-up as (aspects of) a primary need in the former case, but as secondary needs in the latter? The question seems even more appropriate to ask once one realizes that in both cases the data searched after the first look-up would otherwise be present in the lexicographical product because they satisfy the primary needs the product is intended to address. The only answer that appears reasonable is that what is called primary and secondary - needs and data alike 
- is in fact closely related to the function of the specific lexicographical product. Moreover, if, in a systematic cognitive situation, the necessity to consult more than one entry is to be seen as part of the specific primary need, then it must be assumed that primary needs arise in an extra-lexicographical situation and then somehow continue to appear in actual lexicographical situations, until they are satisfied. This is in fundamental disagreement with the very core of the MTLF, according to which the difference between primary and secondary needs is based on their occurrence in, respectively, extra-lexicographical and lexicographical situations. Therefore, the concepts of primary and secondary needs and data need to be redefined, and their status in relation to the concept of the lexicographical function needs to be reconsidered. This is the topic of the next section.

\section{Redefining the basic concepts}

The above discussion of the concepts of secondary needs and data has revealed that the following distinctions postulated by Tarp are either questionable or inadequate if they are to be understood as choices between static, binary opposite categories:

- function-related vs. usage-related,

- $\quad$ primary need vs. secondary need, and

- primary data vs. secondary data.

The critical analysis of the MTLF, as well as of selected data types has yielded the following observations, all of which are in sharp contradiction with Tarp's definitions of primary and secondary needs and data:

(1) Secondary needs are function-related. It follows from the fact that they vary according to the primary need, which itself is always functionrelated.

(2) The satisfaction of primary needs depends on the satisfaction of particular secondary needs. However, at the same time primary needs determine the extent to which a particular lexicographical product can satisfy secondary needs.

(3) The presence, form and content of secondary data types commonly found in the outside matter of a lexicographical product, e.g. the user's guide (and to a significant extent the table of contents too), depend on the function of this product. These data types are therefore functionrelated.

(4) The presence, form and content of secondary data types commonly found in the microstructure of a lexicographical product, e.g. sense indicators or collocational specifications, depend on the function of this product. These data types are therefore function-related. 
(5) Some secondary needs, e.g. the need for a general course in dictionary use, can arise in extra-lexicographical situations, independently of any specific primary needs.

(6) Secondary needs can become primary needs. This happens if the user attempts to satisfy their secondary needs by means of a different lexicographical product than the one chosen to satisfy the original primary need.

(7) Secondary needs can be satisfied by primary data, e.g. the explications of meaning of the headword.

(8) As the user's memory is naturally imperfect, it is beyond the lexicographer's ability to predict some secondary needs and guarantee the inclusion of secondary data that should satisfy them. Therefore, every lexicographical product will at some point of time prove to be imperfect.

(9) Whether similar needs are classified as primary in one case and secondary in another depends on the kind of extra-lexicographical situation that triggers the first consultation of a particular lexicographical product.

(10) Some primary needs, e.g. those related to systematic cognitive situations, can arise, at least partially, in intra-lexicographical situations.

(11) The general, axiomatic principle that for every need for information there are specific data which can satisfy this need exhaustively is not observable in the real world, as the number of secondary needs cannot be reduced to any definable minimum.

(12) The principle that for every need for information there are specific data which can satisfy this need exhaustively is applicable only to some lexicographically relevant needs.

In the light of these results, the notions primary and secondary user needs and data need to be reconsidered. Accordingly, a number of changes to the MTLF are proposed.

First, all lexicographically relevant needs are function-related. Likewise, all data that satisfy these needs are function-related. This is a corollary of observations 1-4 above. Accordingly, the distinction between function-related and usage-related is rejected.

Second, the distinction between primary and secondary needs is retained but modified. On the basis of observations 5, 6, 9 and 10 above, user needs are characterized as follows:

A primary need is a lexicographically relevant need for information. It typically appears in an extra-lexicographical situation. However, in user situations that by definition require multiple consultations of a lexicographical product a primary need can appear in an extra-lexicographical situation 
and continue to reappear in an actual lexicographical situation until it is satisfied.

A secondary need is a lexicographically relevant need for information or instruction and education. It typically appears in an actual lexicographical situation as a result of difficulties with access to or interpretation of specific data meant to satisfy the user's primary need. However, a secondary need can also occur in an extra-lexicographical situation, independently of any specific primary need. The satisfaction of such a need will ideally facilitate the satisfaction of future primary needs.

The categories of primary and secondary needs are dynamic, because a secondary need can become a primary need if the user wishes to satisfy it by means of a different lexicographical product than the one chosen to satisfy their first primary need. Secondary needs can usually be related to specific primary needs although they do not necessarily have to result from them or be satisfied at the same time.

Third, the distinction between primary and secondary data as categories of information data that satisfy, respectively, primary and secondary needs is rejected. This follows from observations 7 and 8 above. Instead, a concept of the use of particular data (types) to satisfy the user's primary or secondary needs is proposed. Accordingly, rather than falling into a set of rigid categories with clear-cut boundaries, various data (types) yield permutations that can satisfy particular primary and secondary needs. Some, but not all, of these permutations can be predicted by the lexicographer on the basis of an analysis of the profile of a potential user and their lexicographically relevant needs. This does not contradict the view that some data types may reveal a propensity to be used to satisfy primary or secondary needs (or both). However, categorizing data types as such makes little sense without referring to a particular function requiring their presence in a lexicographical product.

Finally, two additional conclusions can be drawn from the analysis of secondary needs. First, in line with observations 8, 9 and 11, it must be admitted that the ideal state of lexicography in which the user experiences no secondary needs cannot be achieved. This is due to such factors as technical constraints on the macrostructure of a lexicographical product and the natural disposition of the human mind to forget knowledge and abilities. Although the impossibility to avoid secondary needs stems from these purely practical obstacles, it is only strengthened by the fact that on the theoretical level similar needs can be classified differently as primary or secondary, according to the extra-lexicographical situation triggering them. Second, in the light of observation 12, the MTLF is in need of further development. If a general principle for the theory and practice of lexicography is to be postulated at all, it has to apply to all lexicographically relevant needs of the user. 


\section{Notes}

1. The choice of such a lexicographical product would obviously be preferred provided that the potential dictionary user is a native speaker of English or masters English better than Afrikaans.

2. This definition has recently been replaced by the following one: "An operative situation is defined as one in which a potential user needs help (instructions, directions, etc.) in connection with the completion of a physical or mental operation" (Tarp 2009).

3. Protection when camping, page 2. City-Data Forum, Wyoming. http://www.city-data.com/ forum/wyoming/605955-protection-when-camping-2.html [accessed 15 April 2009].

4. Obviously, this assumption excludes the situation in which a metalexicographer examines the user's guide in one or more dictionaries and subjects the data to a scholarly analysis. However, dictionaries, like all other utility tools, are made to be used rather than to be analyzed. Therefore, it is legitimate here to ignore the specific needs arising in such situations.

5. The dispute of whether a word can have more than one established sense at all, and if so, how to determine what a sense is (cf., e.g. Cruse 2004) will be left to semanticists. Likewise, an idealized state is assumed here, in which specific senses of a given word are universally recognized (although not necessarily represented in the same way in particular dictionaries).

6. It is taken for granted that such a workbook would necessarily have to reflect the function of the dictionary it is associated with. If the workbook is to be treated as a collection of secondary data (as the need it aims to satisfy is secondary), this provides further support for the view that such data are function-related.

7. It is assumed here that the dictionary is suited to the user profile in question and is indeed intended to help the user with text reception. However, even with the best intentions, the lexicographer is certainly not able to predict every word that would be unfamiliar to every user of the dictionary, and consequently, to avoid using these words in the definitions.

8. It should be noted here that not even the Junior Woodchucks Guidebook can satisfy these criteria. From the relevant entry in Wikipedia, one learns that access to data in the Guidebook is through "an extensive index". This is also confirmed in an earlier work by Bergenholtz (1999: 93). Thus, the Guidebook allows for the possibility of secondary needs arising in connection with accessing primary data.

\section{References}

\section{Dictionaries}

Carvajal, C.S. and J. Horwood (Eds.). 2000. The Pocket Oxford Spanish Dictionary. Second Edition. Oxford: Oxford University Press.

LDOCE $=$ Summers, D. et al. (Eds.). 2005. Longman Dictionary of Contemporary English. Fourth Edition with Writing Assistant. Harlow: Pearson Education.

Nielsen, S., L. Mourier and H. Bergenholtz. 2004. Regnskabsordbogen dansk-engelsk. (Danish-English Accounting Dictionary.) Copenhagen: Forlaget Thomson.

Nielsen, S., L. Mourier and H. Bergenholtz. 2007. Regnskabsordbogen engelsk-dansk. (English-Danish Accounting Dictionary.) Copenhagen: Forlaget Thomson.

OED = Oxford English Dictionary Online. http://dictionary.oed.com [accessed 13 March 2009]. Oxford University Press, 2009. 
Merriam-Webster Online Dictionary. http://www.merriam-webster.com [accessed 13 March 2009]. Merriam-Webster, 2009.

Wikipedia. The Free Encyclopedia. http://en.wikipedia.org [accessed 13 March 2009].

\section{Other literature}

Atkins, B.T.S. and M. Rundell. 2008. The Oxford Guide to Practical Lexicography. Oxford: Oxford University Press.

Bergenholtz, H. 1999. Das schlaue Buch. Vermittlung von Informationen für textbezogene und textunabhängige Fragestellungen. Zettersten, A., J.E. Mogensen and V.H. Pedersen (Eds.). Proceedings of the Eighth International Symposium on Lexicography at the University of Copenhagen: 93-110. Lexicographica. Series Maior 90. Tübingen: Max Niemeyer.

Bergenholtz, H. 2008. Concluding Remarks: Lexicographical Tools of Tomorrow. Abstract of a paper delivered at the conference Lexicography at a Crossroads, Aarhus, 19-21 May 2008.

Bergenholtz, H. and S. Tarp. 2003. Two Opposing Theories: On H.E. Wiegand's Recent Discovery of Lexicographic Functions. Hermes 31: 171-196.

Cruse, A. 2004. Meaning in Language. An Introduction to Semantics and Pragmatics. Second Edition. Oxford: Oxford University Press.

Hayashi, T. 1978. The Theory of English Lexicography 1530-1791. Amsterdam Studies in the Theory and History of Linguistic Science, Series III, 18. Amsterdam: John Benjamins.

Nielsen, S. 2006. A Functional Approach to User Guides. Dictionaries. Journal of the Dictionary Society of North America 27: 1-20.

Ptaszynski, M.O. 2008. Anmeldelse af Okoniewski, G. 1999. Dansk-polsk juridisk-merkantil ordbog. ('Review of Okoniewski, G. 1999. Danish-Polish Dictionary of Law and Commerce'.) LexicoNordica 15: 301-316.

Svensén, B. 2004. Handbok i lexikografi. Ordböcker och ordboksarbete $i$ teori och praktik. (Handbook of Lexicography. Dictionaries and Dictionary Making in Theory and Practice.) Second Edition. Stockholm: Norstedts Akademiska Förlag.

Tarp, S. 1998. Leksikografien på egne ben. (Lexicography on its Own Feet.) Hermes 21: 121-137.

Tarp, S. 2006. Leksikografien i grænselandet mellem viden og ikke-viden. Generel leksikografisk teori med særlig henblik på lornerleksikografi. (Lexicography in the Borderland between Knowledge and Nonknowledge. General Lexicographical Theory with Particular Focus on Learner's Lexicography.) Doctoral Thesis. Aarhus: Aarhus School of Business.

Tarp, S. 2008a. Lexicography in the Borderland between Knowledge and Non-knowledge. General Lexicographical Theory with Particular Focus on Learner's Lexicography. Lexicographica. Series Maior 134. Tübingen: Max Niemeyer.

Tarp, S. 2008b. The Third Leg of Two-legged Lexicography. Hermes 40: 117-131.

Tarp, S. 2009. Operative og interpretative funktioner. (Operative and Interpretative Functions.) PowerPoint presentation from the workshop held at the Centre for Lexicography, Aarhus, 3 March 2009.

Yong, H. and J. Peng. 2007. Bilingual Lexicography from a Communicative Perspective. Terminology and Lexicography Research and Practice 9. Amsterdam/Philadelphia: John Benjamins.

Wiegand, H.E. 1984. On the Structure and Contents of a General Theory of Lexicography. Hartmann, R.R.K. (Ed.). LEXeter '83 Proceedings. Papers from the International Conference on Lexicography at Exeter, 9-12 September 1983: 13-30. Lexicographica. Series Maior 1. Tübingen: Max Niemeyer. 